\title{
Nota editorial
}

Valencia, 19 de diciembre de 2016.

El número 34 de los CEFD está compuesto por quince artículos y varias recensiones bibliográficas, ilustrativos de algunas de las preocupaciones más acuciantes de la filosofía jurídica y política actual. Es la pretensión que queremos mostrar al editar esta revista digital de forma bimestral, que tiene un doble e inequívoco sentido: tanto divulgativo como académico, básicamente orientado en torno a una preocupación fundamental por la defensa de los derechos humanos, tanto a un nivel cuantitativo (amplitud del número de sus potenciales lectores) como cualitativo (pretendida importancia de los trabajos recogidos).

Es la razón fundamental para mantener los esfuerzos por mejorar la calidad, el nivel de indexación y sobre todo su internacionalización. Uno de los resultados más satisfactorios de este trabajo continuo ha sido la exitosa y reciente superación de la quinta convocatoria de evaluación de la calidad editorial y científica de las revistas españolas, llevada a cabo por la Fundación Española para la Ciencia y la Tecnología (FECYT). El Sello de Calidad FECYT, obtenido en el mes de julio de 2016, supone un certificado de excelencia editorial y científica con una vigencia trianual, lo que supone un éxito sin duda muy importante. Por tanto, tras la obtención de este sello de calidad, además de otros reconocimientos y certificaciones logradas anteriormente, los CEFD se han posicionado entre las mejores revistas 
especializadas en el ámbito de las ciencias jurídicas y sociales; así se encuentra en línea ascendente y en una dinámica adecuada si se tiene en cuenta los porcentajes y los últimos índices de calidad y de clasificación de las revistas especializadas, tal y como se muestra en la referencia a las plataformas de evaluación, indexación y/o impacto de revistas científicas que figura en la página principal de la revista.

Así pues, les invitamos a que consulten este último número de la publicación.

Un saludo cordial.

Mario Ruiz Sanz

Director de los CEFD. 